Agriculture, Agribusiness and Biotechnology

Vol.59: e16160518, January-December 2016 http://dx.doi.org/10.1590/1678-4324-2016160518 ISSN 1678-4324 Online Edition

\title{
Research on the spatial distribution characteristics of arable land economic quality composite grade and ecology environment in Yunnan Province, China
}

\author{
Gengjie ZHANG ${ }^{1,2,3}$;Chuan ZHANG ${ }^{1,2,3^{*}}$, ShuxiaLiu ${ }^{1,2,3}$ and Honggang Zheng ${ }^{1,2,3}$. \\ ${ }^{1}$ Land Resources Science and Technology Engineering Research Center of Yunnan Agricultural University, \\ Kunming 650201 $;^{2}$ Engineering Laboratory of Land Resources Utilization and Protection of Yunnan Province, \\ Kunming 65020. ${ }^{3}$ Field Scientific Observation \& Research Bases of Land Use in Yunnan Luliang, Ministry of Land \\ and Resources.
}

\begin{abstract}
Understanding the distribution characteristics of arable land in Yunnan Province is of significant importance to make scientific decisionsto use and improve the quality of arable land. In this study, the distribution characteristics of the arable land grade including 129 counties were analyzed based on the accomplishment of cultivated land classification in Yunnan Province. The results showed that the average economic quality composite grade was 2.9, in a range of 1 to 13, which means that the economic quality of arable landof Yunnan Province is relatively lower. In excellent zone, the grade ranges from 1 to 10, and the average grade is 2.4. In good zone, it ranges from 1 13, and the average grade is 3.1. In medium zone, it ranges from 1 12, and the average value is 3.2. In poor zone, it ranges from 1 11, and the average is 3. In worse zone, it ranges from 1 10, and the average is 2.2. The middle and poor arable land has the largest area, which concentrated in the middle and poor zones and dominantly influenced the average grade in the whole province. This research will serve as a reference forarable landpolicy making in the future, especiallyon apace arrangement optimization, quality improvement and ecology environment protection in Yunnan Province.
\end{abstract}

Key words: arable land, economic quality composite grade, distribution, ecological environment, Yunnan Province

*Authors for correspondence: zhangchun82@sina.com 


\section{INTRODUCTION}

Arable land is as an important carrier forhuman and social development andvery closely related to human survival and development. Economic quality composite gradeof arable landcould be used as a parameter to study theinfluence from human factors, and affects social stability and

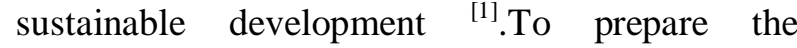
implement "Land Management Law ofPeople's Republic of China", which requires scientific, rational, unified, strict management ofcultivated land resources, improved management level of arable land resources, and to provide scientific basis forland use planning and land use management, Yunnan Province has been carrying outprovince-wide arable land quality evaluation since 2004,and agricultural land classification workwas accomplished in this background ${ }^{[2-}$ ${ }^{4]}$.Yunnan agricultural land classification is an investigationimplemented to evaluatearable land qualityof the province with unified technical specifications and is based oncounty-level administrative regions. The results can fully reflectnatural conditions of arable land, whichprovides accurate arable landquality information for land and resources administration [5-8].

Yunnan province is the region with most severeconflicts between people and land,which typically exists in ecologically fragile and less developed region.With the current urbanization process, the protection of arableland resources of the region face greater pressure.Starting from the province of spatial pattern,the understanding of distribution characteristic of arable land and will providea basis to determinescientific measures for the quality improvement and protection of arable landis needed.This study on thedistribution of arable landeconomic quality composite grade is mainlybased on natural conditions of arable land,economic quality grade,production capacity, etc. less in combiningeconomic quality composite grade andstatus of ecologic environment ${ }^{[9-16]}$. Based on agricultural land classification results and the combinedevaluation results of ecological environment of Yunnan Province, this study analyzed spatial distribution characteristics ofeconomic quality composite grade ofthe province's arable land, with a view toprovide a basis for differentiated arable land use and protection policy.

1General Background of the Study Areaand Data Sources

General Background of the Study Area

Located in the southwest of China, Yunnan Province borders Asian mainland in the North, and connects Southeast Asia Peninsula in the south. Under control of southeast and southwest monsoons, its environment is also affectedby Tibetan Plateau, presenting a complex and diverse natural geographical environment.Yunnan administrative district now consists of 16 cities,,129 counties (cities, districts), and hasa total land area of 394,000 square kilometers.Among them, arable land accounts for $15.97 \%$ of the province,garden plot $2.12 \%$, forest area $57.69 \%$, grassland $2.05 \%$.

Yunnan province is of mountain plateau terrain dominant by mountainous regions. The province's terrain is higher in the northwest, lower in southwest and southeast. With undulating terrain, it isalternatively distributed withmountains, plateaus, basins and valleys, forming a complex and diverse landform. Mountains, hills andintermountain basins are the main landform,in which mountains account for $84 \%$ of the total area of the province,hills account for around $10 \%$,intermountain basinsaccount for the rest $6 \%$.Arableland is mainly distributed in basinsand mountainous areas.Sloping farmlandaccounts for 64\% of total arable land and arefragmentarily scattered withserious soil erosion andlow production capacity ${ }^{[17]}$.

\section{Data Sources}

Provincial summary results of agricultural land classification of 129 counties (cities, districts) in Yunnan Province plusstatus evaluation results of ecological environment in Yunnan Provincial comprehensive remote sensing project of territorial resources are taken as the data base of this study. According to the provincial classification achievements, arable land economic quality composite grade increases and becomes better as figures increase.

\section{DATA PROCESSING AND ANALYSIS METHOD}

Data Processing Method 
Provincial summary database of agricultural land classification in the province's 129 counties (cities, districts) is taken as data base for the analysis. Spatial overlay analysis is performed by combining integrated remote sensing survey data of Yunnan Provincial territorial resources with ArcGIS as spatial analysis platform. And differentiation characteristics of provincial classification in space is analyzed.

Through the combination of mechanical input costs per unit area of farming, sowing, harvest; water, electricity, diesel fuel and other expenses per unit area; seeds, fertilizers, pesticides, plastic film and other costs per unit area, local labor costs, transportation costs for agricultural products, agricultural product prices in the provincial area, and following standard farming system, the index of arable land economic quality composite grade was calculated in accordance with comprehensiveland economic coefficient undercertain natural conditions,average land-use conditions, average landeconomic conditions. The calculation method for integrated land economic coefficientis described in the following formula.

$G i=Y i \cdot K c=R i \cdot K l \cdot K c \quad$ (1)

Wherein, Gi represents index of arable land economic quality composite grade of $i$-th classification unit; $Y i$ represents arable land utilization index of $i$-th classification unit; $K c$ represents integrated land economic coefficient of classification unit in equivalence region; $R i$ representsarable land nature grade index of $i$-th classification unit; $K l$ represents integrated arable land utilization coefficient of classification unit in equivalence region.As shown in the equation, economic quality composite grade derives from utilization grade and nature grade,reflectingtransitivity andcorrelation. So results ofeconomic quality composite grade canbetter comprehensively represent objective quality of arable land.

In this study, to calculate the average economic grade within the region, the area weighted average method is adopted, which isunderthe premise that total area of various grades is calculated out, carry out area weighting of various grades ${ }^{[18-20]}$.

$Y=\frac{\sum_{i=i \min }^{i \max } i \times S_{i}}{S_{T}}$

In the formula, $Y$ represents average economic quality composite grade of the area; $i$ represents economic quality composite grade ofarable land $; i_{\text {min }}$ is the minimum grade $; i_{\max }$ is the maximum grade; $S_{i}$ represents agricultural acreage of $i, \mathrm{hm}^{2}$; $S_{T}$ represents total agricultural acreage of the region, $\mathrm{hm}^{2}$.

\subsection{Spatial Analysis}

Agricultural land classification results of 129 counties (cities, districts) are taken as data base for the analysis. Spatial analysis capabilities of ArcGIS software was applied in this study, and the results are converted. With spatial overlay analysis, statistical analysis, comprehensive analysis and other analysis methods, distribution characteristics of arable land utilization in zone scale of status evaluation of ecological environment was analyzed.

\section{RESULTS AND ANALYSIS}

Quantitative DistributionCharacteristics of Arable Land Economic Quality Composite Grades

According to the agricultural land classification results of Yunnan Province, arable land consisting of 13,868 provincial evaluation units has a total area of 6.1195 million $\mathrm{hm}^{2}$. There are 13 grades in economicquality composite grade of arable land, ranging from 1 to 13 , of which grade 1 represents the lowesteconomic level, and grade 13 represents thehighest economic level. Theaverage area weighted is 2.9.As shown in Figure 1,the economicquality composite grade of arable land of Yunnan Province has a typical skewed distribution, generally low in grades. Arable land of grade 2 has the highest number, accounting for $28.63 \%$. While grade 13 has the minimum number, accounting for only $0.01 \%$. The province'seconomicquality composite grade of arable land mainly is between $1 \sim 4$, witha total area of $5257393.84 \mathrm{hm}^{2}$, accounting for $85.91 \%$. Thearable land with economicquality composite grade between $5 \sim 13$ is $865127.44 \mathrm{hm}^{2}$ in area, accounting for $14.09 \%$.

Depending on the scope of the province's economic quality composite gradeof arable land, the arable land was classified into four grades: poor (grade 1 3), medium (grade 4 6), higher (grade 7 9) and excellent (grade 10 13). Poor land inYunnan province has an area of $4334891.09 \mathrm{hm}^{2}$, accounting for $70.84 \%$ ofthe province's total cultivated area. Medium land is 
$1537868.62 \mathrm{hm}^{2}$,accounting for $25.13 \%$.Higher land is $222062.33 \mathrm{hm}^{2}$, accounting for $3.63 \%$;Excellent land is $24729.24 \mathrm{hm}^{2}$, accounting for only $0.40 \%$.

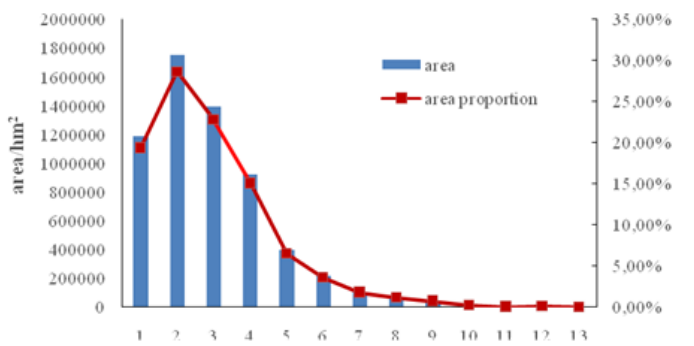

Figure 1. Structure of arable land economic quality composite grade in Yunnan Province

Distribution Characteristic of Arable Land Economic Quality Composite Grades on Ecological Environment Assessment Zone

According to Yunnan provincial territorial resources remote sensing integrated survey project, Yunnan Province satellite remote sensing data is taken as the information source, with dominant factor, regional differences,overall consideration and operability as selection principles of index, 6 indexes of forest coverage rate, water resources per square meter of soil, slope dryland proportion, proportion of unused land, soil erosion rate, population density are selected, and then ecological environment of the province is divided into five grades, i.e. excellent zone, good zone, medium zone, poor zone and worse zone $^{[21,22]}$.Excellent ecological environment zonein Yunnan Province ismainly distributed in lake basin of central Yunnan plateau, mountains and canyons innorthwest Yunnan and broad valley insouthwest Yunnan. Good and medium zones are distributed throughout the whole province; while poor zone is mainly distributed inlake basin of central Yunnan plateau,hilly plain insoutheastYunnan andmountain plateau innortheast Yunnan. The worse zone ismainly distributed inmountain plateau innortheast Yunnan.

As shown in Figure 2 and Table 1, Yunnan Province agricultural land classification results was overlapped with the province's ecological environment statuszone, from which it can be clearly seen that except worse zone, there isn't any significant differences in the number of evaluation units between each zone.The total area of arable land represents the majority in medium zone. Theaverage singleagricultural acreage in worse

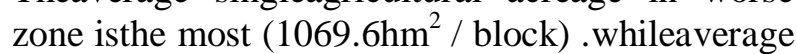
singleagricultural acreage inexcellent zone is the lowest $\left(302.59 \mathrm{hm}^{2} /\right.$ block. $)$

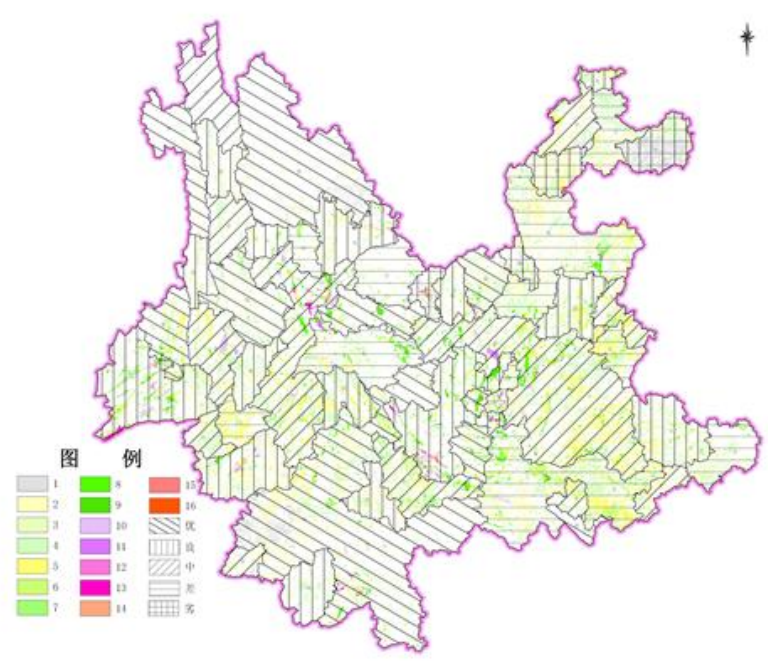

Figure 2. The overlapped chart of land economic quality composite grade and ecological environment in Yunnan Province

Table 1 - Overlay of land economic quality composite grade and ecological environment in Yunnan Province

\begin{tabular}{lllll}
\hline & number & number per $(\%)$ & area $\left(\mathrm{hm}^{2}\right)$ & area per $(\%)$ \\
\hline excellent zone & 3622 & $26.12 \%$ & 1095998.02 & $17.91 \%$ \\
\hline good zone & 3552 & $25.61 \%$ & 1337564 & $21.86 \%$ \\
\hline medium zone & 3599 & $25.92 \%$ & 1800466.57 & $29.42 \%$ \\
\hline poor zone & 2749 & $19.82 \%$ & 1515457.5 & $24.76 \%$ \\
\hline worse zone & 346 & $2.49 \%$ & 370065.41 & $6.05 \%$ \\
\hline total & 13868 & $100 \%$ & 6119551.5 & $100 \%$
\end{tabular}

(1) Distribution Characteristic of Arable Land Economic Quality Composite Grade in Excellent Zone
In present status of ecologic environment, arable land economic quality composite grade of excellent zone is distributed in therange of 1 10. 
As shown in figure 3, distribution of arable land grade in the zone is of skewed normal distribution, andarea weighted average grade is 2.41. The agricultural acreage ofgrade 1 has the highest area of $419053.61 \mathrm{hm}^{2}$, accounting for $38.23 \%$; and agricultural acreage ofgrade 9 has the lowest area of,2159.79 $\mathrm{hm}^{2}$, which is close to zero. Distribution of arable land economic quality composite grade ofexcellent zone is similar to that of provincial land economic quality composite grade,mainly in 1 4, with a total area of $976068.74 \mathrm{hm}^{2}$, accounting for $89.06 \%$.

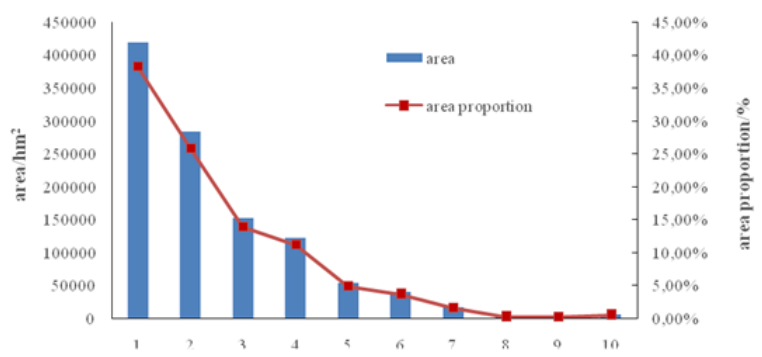

Figure3. The structure of arable land economic quality composite grade in excellent zone

(2) Distribution Characteristic of Arable Land Economic Quality Composite Grade in Good Zone In present status of ecologic environment, arable land economic quality composite grade of good zone is distributed in the range of 1 13. As shown in figure 4, distribution of arable land grade in the zone is of skewed normal distribution, andarea weighted average grade is 3.1.The agricultural acreage ofgrade 2 has the highest area of $429233.32 \mathrm{hm}^{2}$, accounting for32.09\%;and agricultural acreage ofgrade 13 has the lowest area of, $573.87 \mathrm{hm}^{2}$, accounting for $0.04 \%$.Distribution ofarable land economic quality composite grade of goodzone is similar to that of provincial land economic quality composite grade, mostly in $1 \sim 4$, with a total area of $1118926.23 \mathrm{hm}^{2}$, accounting for $83.65 \%$.

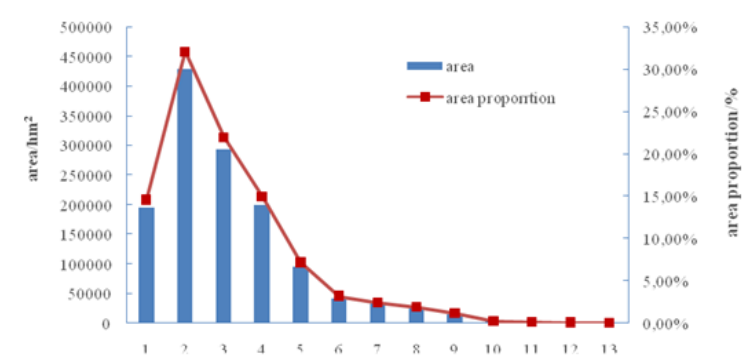

Figure 4. Thestructure of arable land economic quality composite grade in good zone
(3) Distribution Characteristic of Arable Land Economic Quality Composite Grade in Medium Zone

In present status of ecologic environment, arable land economic quality composite grade ofmedium zone is distributed in therange of 1 12.As shown infigure 5,distribution of arable land grade in the zone is of skewed normal distribution,andarea weighted average grade is 3.2.The agricultural acreage ofgrade 2 has the highest area of $500816.99 \mathrm{hm}^{2}, \quad$ accounting for 27.82 $\%$;agricultural acreage ofgrade 11 has the lowest area of, $2124.22 \mathrm{hm}^{2}$, accounting for 0.12 $\%$.Distribution ofarable land economic quality composite gradeof mediumzone is similar to that of provincial land economic quality composite grade,mostly in 1 4, with a total area of $1480013.05 \mathrm{hm}^{2}$, accounting for $82.20 \%$.

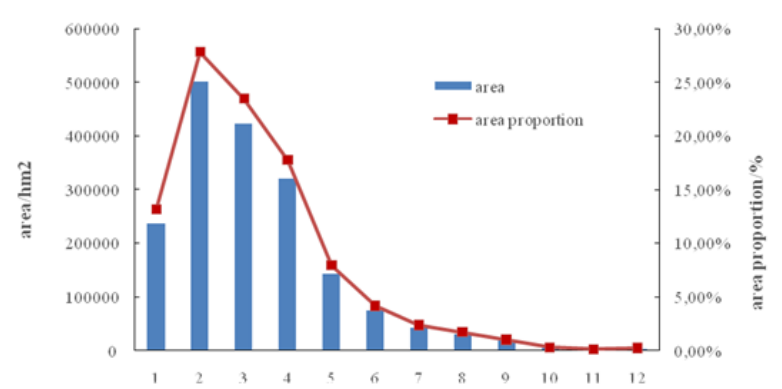

Figure 5. Thestructure of arable land economic quality composite grade in medium zone

(4) DistributionCharacteristic of Arable Land Economic Quality Composite Grade in Poor Zone In present status of ecologic environment, arable land economic quality composite grade ofpoor zone is distributed in therange of 1 11.As shown in figure 6,distribution of arable land grade in the zone is of skewed normal distribution,andarea weighted average grade is 3.0.The agricultural acreage ofgrade 2 has the highest area of $435080.44 \mathrm{hm}^{2}$, accounting for 28.71 $\%$;agricultural acreage ofgrade 11 has the lowest area of $6.09 \mathrm{hm}^{2}$, close to 0.Distribution ofarable land economic quality composite gradeof poorzone is similar to that of provincial land economic quality composite grade,mostly in 1 4 , with a total area of $1323182.56 \mathrm{hm}^{2}$, accounting for $87.31 \%$. 


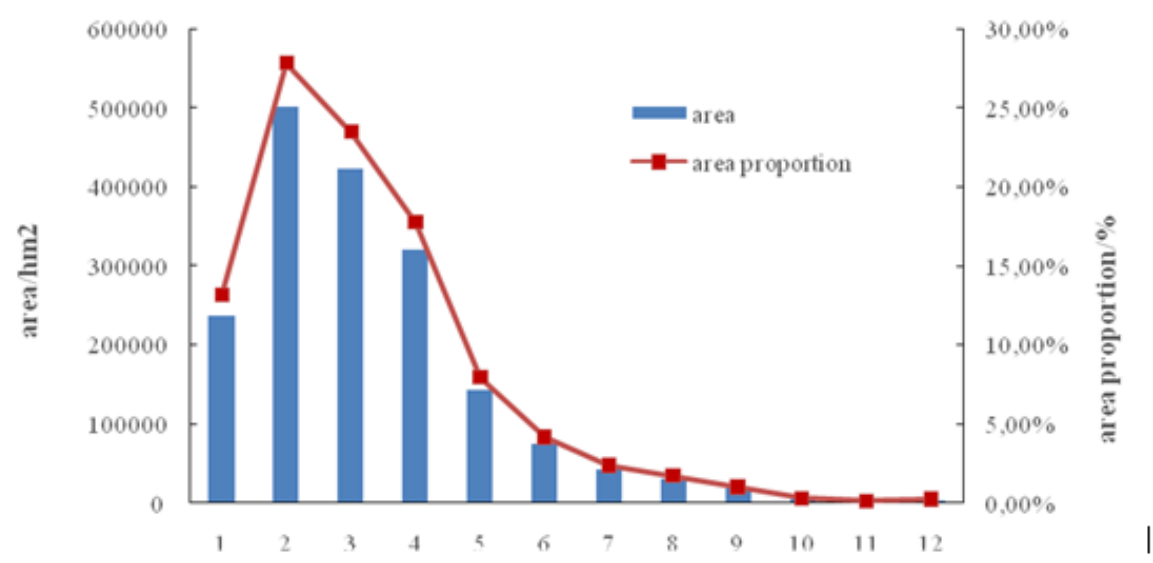

Figure 6 - The structure of arable land economic quality composite grade in poor zone

(5) Distribution Characteristic of Arable Land Economic Quality Composite Grade in Worse Zone

In present status of ecologic environment, arable land economic quality composite grade of poor zone is distributed in the range of 1 10. As shown in figure 7, distribution of arable land grade in the zone is of skewed normal distribution, and area

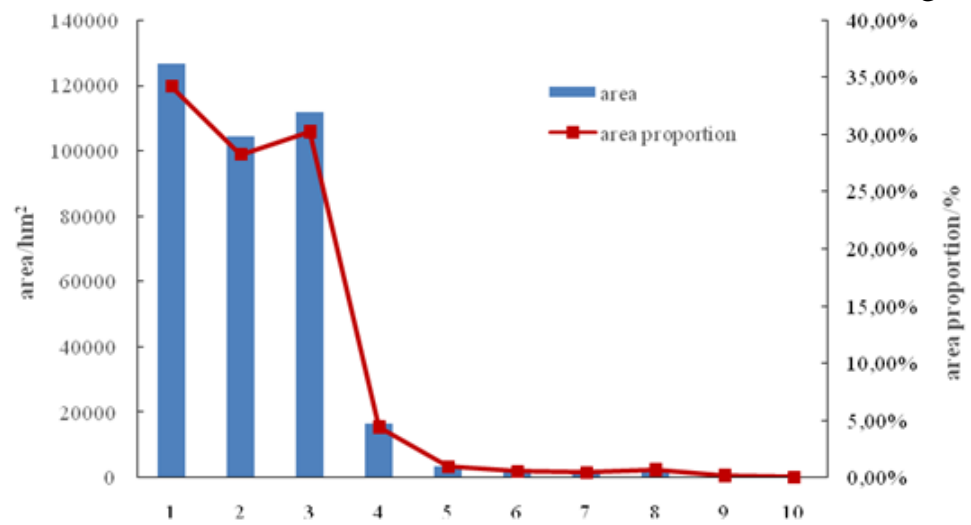

Figure 7 - Structure of arable land economic quality composite grade in worse zone

Arable Land Economic Quality Composite Grade in Ecological Environmental Evaluation Zone According to analysis of arable land economic quality composite grade in Yunnan in status zone of ecological environment, arable land economic quality composite grade in each ecological zone is of skewed normal distribution, mainly land in weighted average grade is 2.2 . The agricultural acreage of grade 1 has the highest area of 126474.8 $\mathrm{hm}^{2}$, accounting for $34.28 \%$; agricultural acreage of grade 10 has the lowest area $235.41 \mathrm{hm}^{2}$, accounting for $0.06 \%$. Distribution of arable land economic quality composite grade of worse zone is mainly between $1 \sim 3$, with a total area of $342889.23 \mathrm{hm}^{2}$, accounting for $92.66 \%$.

medium and low grade. Take arable land economic quality composite grade as the research focus, conduct horizontal and vertical analysis and comprehensive analysis in different ecological zones. See below for the details. 
Research on spatial distribution characteristics

Table 2. The average economic quality composite grade of arable land in different ecological environment zones in Yunnan Province

\begin{tabular}{|c|c|c|c|c|c|c|c|c|c|c|c|}
\hline & \multicolumn{2}{|c|}{ Excellent zone } & \multicolumn{2}{|c|}{ Good zone } & \multicolumn{2}{|c|}{ Medium zone } & \multicolumn{2}{|l|}{ Poor zone } & \multicolumn{2}{|c|}{ Worse zone } & \multirow[b]{2}{*}{$\begin{array}{l}\text { Avera } \\
\text { ge } \\
\text { grade } \\
\text { in } \\
\text { summ } \\
\text { ery }\end{array}$} \\
\hline & $\begin{array}{l}\text { Agricult } \\
\text { ural } \\
\text { acreage } \\
/ \mathrm{hm}^{2}\end{array}$ & $\begin{array}{l}\text { Avera } \\
\text { ge } \\
\text { grade }\end{array}$ & $\begin{array}{l}\text { agricult } \\
\text { ural } \\
\text { acreage } \\
/ \mathrm{hm}^{2}\end{array}$ & $\begin{array}{l}\text { Avera } \\
\text { ge } \\
\text { grade }\end{array}$ & $\begin{array}{l}\text { agricult } \\
\text { ural } \\
\text { acreage } \\
/ \mathrm{hm}^{2}\end{array}$ & $\begin{array}{l}\text { Avera } \\
\text { ge } \\
\text { grade }\end{array}$ & $\begin{array}{l}\text { agricult } \\
\text { ural } \\
\text { acreage } \\
/ \mathrm{hm}^{2}\end{array}$ & $\begin{array}{l}\text { Avera } \\
\text { ge } \\
\text { grade }\end{array}$ & $\begin{array}{l}\text { agricult } \\
\text { ural } \\
\text { acreage } \\
/ \mathrm{hm}^{2}\end{array}$ & $\begin{array}{l}\text { Avera } \\
\text { ge } \\
\text { grade }\end{array}$ & \\
\hline $\begin{array}{l}\text { Excellent } \\
\text { land }\end{array}$ & 0 & -- & 6230.81 & 10.9 & $\begin{array}{l}11331.5 \\
7\end{array}$ & 10.9 & 1431.73 & 10 & 235.41 & 10 & 10.8 \\
\hline $\begin{array}{l}\text { Higher } \\
\text { land }\end{array}$ & $\begin{array}{l}21321.2 \\
1\end{array}$ & 7.3 & $\begin{array}{l}73391.1 \\
9\end{array}$ & 7.8 & $\begin{array}{l}91125.2 \\
1\end{array}$ & 7.7 & $\begin{array}{l}31222.4 \\
2\end{array}$ & 7.8 & 5002.3 & 7.8 & 7.7 \\
\hline $\begin{array}{l}\text { Medium } \\
\text { land }\end{array}$ & $\begin{array}{l}215306 . \\
05\end{array}$ & 4.6 & $\begin{array}{l}339005 . \\
68\end{array}$ & 4.5 & $\begin{array}{l}537736 . \\
98\end{array}$ & 4.5 & $\begin{array}{l}423881 . \\
45\end{array}$ & 4.5 & $\begin{array}{l}21938.4 \\
7\end{array}$ & 4.4 & 4.5 \\
\hline Poor land & $\begin{array}{l}853871 . \\
05\end{array}$ & 1.7 & $\begin{array}{l}918936 . \\
1\end{array}$ & 2.1 & $\begin{array}{l}116027 \\
2.8\end{array}$ & 2.2 & $\begin{array}{l}105892 \\
1.91\end{array}$ & 2.2 & $\begin{array}{l}342889 . \\
23\end{array}$ & 2 & 2.1 \\
\hline Summery & $\begin{array}{l}1090498 \\
.31\end{array}$ & 2.4 & $\begin{array}{l}133756 \\
3.78\end{array}$ & 3.1 & $\begin{array}{l}180046 \\
6.56\end{array}$ & 3.2 & $\begin{array}{l}151545 \\
7.51\end{array}$ & 3 & $\begin{array}{l}370065 . \\
41\end{array}$ & 2.2 & 2.9 \\
\hline
\end{tabular}

(1)Horizontal Analysis of Arable Land Economic Quality Composite Grade in Various Ecological Environment Zones

Horizontal analysis is to analyze arable landeconomic quality composite grade in the same grade range but in different ecological environment zones.

Within the range of excellent land,arable landarea percentage of excellent zone, good zone, medium zone, poor zone and worse zone are $0,32.40$ $\%, 58.93 \%, 7.45 \%$ and $1.22 \%$ respectively;As seen from average economic quality composite grade of excellent land, there is noexcellent land inexcellent zone. The average economic quality composite grade of good and medium zone is the most. While in other ecological zones they have little difference and average economicquality composite grade in summary is 10.8 . In the range ofhigher land, arable landarea percentages of excellent zone, good zone, medium zone, poor zone and worse zone are 9.60\%, 33.05\%, 41.04\%, $14.06 \%$ and $2.25 \%$ respectively. In the perspective of average economic quality composite grade,good zone, medium zone, poor zone and worse zone are essentially the same, The excellent zone is thelowest, with average economic quality composite grade of 7.7. Within the range ofmedium land,arable landarea percentage of excellent zone, good zone, medium zone, poor zone and worse zone are $14.00 \%, 22.04 \%$, $34.97 \%, 27.56 \%$ and $1.43 \%$ respectively.In the perspective of average economic quality composite grade,various ecological zones arebasically the same, and the total average economic quality composite grade is 4.5.Within the range of poor land,arable landarea percentage of excellent zone, good zone, medium zone, poor zone and worse zone are $19.70 \%, 21.20 \%$, $26.77 \%, 24.43 \%$ and $7.91 \%$ respectively. From the view of average economic quality composite grade,agood zone, medium zone, poor zone and worse zonearebasically the same, comparatively lower excellent zone is slightly whose average economic quality composite grade in summary is 2.1 .

(2) Vertical Analysis of Arable Land Economic Quality Composite Grade in Various Ecological Environment Zones

Vertical analysis is to analyze arable landeconomic quality composite grade indifferentgrade ranges and inthe same ecological environment zone.

In the excellent zone, area percentages of excellent land, higher land, medium land and poor land are $0,1.96 \%, 19.79 \%$ and $78.30 \%$ respectively. Asarea of poor land contributes the most,the average economic quality composite grade ofarable landin the entire excellent zone tends to be low withgrade of 2.4.Ingood zone, area proportions of excellent land, higher land, medium land and poor land are $0.47 \%, 5.49 \%, 25.35 \%$ and $68.70 \%$ respectively., 
As poor land is the majority, theaverage economic quality composite grade ofarable landin the entire good zone isalso low, with anaverage economic quality composite grade of 3.1 , which is middle or slightly low.In mediumzone, area percentage of excellent land, higher land, medium land and poor land are $0.63 \%, 5.06 \%, 29.87 \%$ and $64.44 \%$ respectively. poor land is largest proportion.So the average economic quality composite grade ofarable landin the zone tends to bemiddle or slightly low withgrade of 3.2. In poor zone,area percentage of excellent land, higher land, medium land and poor land are $0.09 \%$, $2.06 \%, 27.97 \%$ and $69.87 \%$ respectively. In which poor land is still the one that affectsaverage economic quality composite grade. As a result, the overall average economic quality composite gradealso tends to be low, with a grade of 3 . In worse zone,area percentage of excellent land, higher land, medium land and poor land are $0.06 \%, 1.35 \%, 5.93 \%$ and $92.66 \%$ respectively. The poor land also contributes the most to the average economic quality composite grade of arable landso itsaverage grade is low with a grade of 2.2 .

(3) Comprehensive Analysis of Arable Land Economic Quality Composite Grade in Various Ecological Environment Zones

By combining vertical and horizontal analysis ofarable land economic quality composite grade in various ecological environment zones, the overall distribution of arable land quality in Yunnan Province can be reflected by.the degree of correlation and coordination effect

Despite excellent zone has the bestnatural ecological environment, it is mainly distributed in the valleys which commonly are the gathering places of ethnic minorities, so theagricultural technology and production input per unit area is relatively low. Their low level of industrialization andirrational industrial structure negatively impacts economic factors of arable land, as a result the overall average economic quality composite grade is lower than the provincial average grade ${ }^{[23]}$.Good zone and medium zoneare distributed throughoutthe province, of which,arable land is more distributed in flatland region andvalley area with the best light, heat, water, and soil conditions. Social economy is the mostdeveloped withthe highest planting level.Althoughnumber ofarable land ofdifferent grades in medium zone isslightly higher than that in good zone, seen fromarea weighted average, the overall quality of arable land in medium zone and in good zone are equivalent, both of which has higher averageeconomic quality composite gradethan the provincialaverage grade.Poor zone and worse zone are mainly concentrated in Southeast, Northeast Yunnan. On the one hand, there is muchlimestonein the zone, withsloping farmland and dry land as the main, which limits investment and management of arable land utilization conditions. On the other hand,the zone has largepopulation density and single cropping system.In comparison, natural conditions and ecological environment of worse zone is worse, in terms ofwater conservancy, transportation and other infrastructure, labor quality is generally. As a result, arable land averageeconomic quality composite grade of worse zone is lower than the provincial average grade.

\section{CONCLUSIONS AND DISCUSSIONS}

(1) Treating Yunnan Province as a whole, this study comprehensively applied agricultural land classificationdata of 129 counties (cities)to analyze the province's characteristics of arable land economic quality composite grade, and explained the spatial distribution characteristics of arable land economic quality composite grade.

(2)Overallthe arable land economic quality composite grade of Yunnan Province is relatively low, with an average economic quality composite grade of 2.9. The province's arable land economic quality composite grade is mainly in the range of 2-6, whichrepresents $82.30 \%$ in total.

(3) Poor land, which represents $70.90 \%$ ofthe province's arable land, accounts for the largest proportion, while excellent land has the smallest area and only accounts for $0.31 \%$.

(4) Differences exist in the distribution of arable land economic quality composite grade in ecological environment zones. Overall, arable land grade of medium zone is slightly higher with a grade of 3.2; and the worse zone is the lowest, grade

This paper conducted a combined analysis of distribution of arable land economic quality composite grade and ecological environment zones in Yunnan Province from a macro perspective. County-level administrative unitwas used in this study asthe evaluation units in Yunnan ecological environment zoning, which provides new ideas forjoint analysis of arable landeconomic quality 
composite grade and ecologicalenvironment zone. On the other hand, further studies may be conducted in the future unveil the linkages between distribution of arable land economic quality composite grade and ecological environment zones in Yunnan Provincefactors influencing arable land economic quality composite grade reasons explaining the differences in arable land economic quality composite grade and howto specifically guide future land utilization and protection.

\section{ACKNOWLEDGEMENT}

The paper is funded by the National Science \& Technology Pillar Program during the $12^{\text {th }}$ Fiveyear Plan Period (2015BAD06B04)

\section{REFERENCES}

[1] Peng Jian, Jiang Yijun, Liu Song.Progress and Prospects of Agricultural Land Classification Research in China [J].Chinese Journal of EcoAgriculture, 2005,13 (4): 167-170.

[2] Zhang Yaowu, Yu Jianxin. Investigation and Evaluation of Arable Land Quality Grade in China (Yunnan Volume) [M]. Beijing: China Land Press, 2010.

[3] KongXiangnin, Zhang Qingpu. Spatial Distribution Characteristics of Arable Land Grade in China's Western Region[J].Transactions of the Chinese Society of Agricultural Engineering, 2012,28 (22): 1-7.

[4] Yan Ning, Zheng Honggang, Yu Jianxin, et al. Study on Provincial Data Collection Method of Yunnan Agricultural Land Classification[J].China Land Science, 2009,32 (8): 31-35.

[5] Yan Ning, Zheng Honggang, Yu Jianxin, et al.Study on Applying Agricultural Land Classification in Basic Farmland Division[J].Territory \& Natural Resources Study, 2009,21 (03): 28-30.

[6] Wang Bo, Zheng Honggang, LiuShuxia, et al. Study on Applying Yunnan Province Agricultural Land Classification Resultsin Basic Farmland Protection[J].Journal of Yunnan Agricultural University, 2009,24 (1): 100-103.

[7] PengErrui, Wang Sui, HaoLisha, et al. Study on Protection Status and Countermeasures of Arable Land and Basic Farmland in Yunnan Province [J]. Resources \& Industries, 2009,11 (4): 59-63.

[8] SiZhenzhong, Li Mao, QiuWeili et al. Regional Differences and Protection of Arable Land Resources in China [J].Journal of Natural Resources, 2010,25 (5): 713-721.

[9] Wang Hongbo, Cheng Feng, ZhangZhongfan et al. Differentiation Characteristics of Chinese
ArableGrade andTheir Impact on Arable Land Protection [J].Transactions of the Chinese Society of Agricultural Engineering, 2011,27 (11): 1-8.

[10] LiuYuwang, Wang Bo. Study on Regional Distribution Law of Yunnan Agricultural LandUtilizationGrade[J] Resources \& Industries, 2008,10 (5): 83-87

[11] Zhang Qingpu, KongXiangbin, Yun Wenju .Grade Distribution Law oOf Chongqing City Before and After National Agricultural Land Classification Summary[J].Transactions of the Chinese Society of Agricultural Engineering, 2010,26 (10): 297303.

[12] RenKui, ZhouShenglu, Zhang Hongfu, et al.Study on Spatial Pattern and Influence Mechanism of JiangsuFarmland Resources Quality [J].Transactions of the Chinese Society of Agricultural Engineering, 2008,24 (4): 127-134.

[13] Xu Yan, WuKening, ChengXianjun. Analysis of Productivity Spatial Variation Law and Leading Factor of Productivity Increase of Northeast Arable Land[J]. Resources Science, 2011,33 (11): 2030-2040.

[14] JiaShuHai, QiuZhiwei, Pan Jinhua, et al. Spatial Distribution and Influencing Factors of Liaoning Province Agricultural Land Quality [J].Chinese Journal of Soil Science, 2011,42 (2): 273-279.

[15] Cui Xuhui. Distribution Characteristics of Gansu Agricultural Land Economic Quality and CauseAnalysis[J].Modern Business, 2013,5 (16): 90-92.

[16] Zhao Youchen.Agricultural Land EconomicQuality Assessment and Spatial Distribution Research -with Anhui Province as an Example [J].Rural Economy and ScienceTechnology, 2014,20 (8): 19-21.

[17] Wang Bo. Study onSpatial Distribution Law of Agricultural Land Utilization Grade in Broad Valley Area of Southern Yunnan[D].Yunnan Agricultural University, 2008.

[18] TD / T 1004-2003, Agricultural Land Classification Regulations [S].

[19] Zhang Fengrong, Xu Yan, Zhang Jinke et al. Theory, Methods and Practice of Classification and Appraisal of Agricultural Land [M]. Beijing: China Agricultural University Press, 2008.

[20] Yun Wenju.Chinese Arable Land Classification and Monitoring Studies [M]. Beijing: China Land Press, 2010.

[21] Xu Jing, Fu Baohong. Ecological Environment Assessment of Yunnan [J] Ecological Economy, 2002,25 (7): 45-49.

[22] MengGuangTao, Fang Xiangjing, HeLiping, et al. Ecological Environment Status Quo of Yunnan Province and Countermeasures [J].Research of Soil and Water Conservation, 2006,13 (2): 7-10.

[23] Zou Yue, Fan Yi, Zheng Honggang. Study on Influence of Altitude Factors on Agricultural Land 
Utilization Index[J] Yunnan Agricultural University, 2009,24 (2): 274-277.

Received: June 15, 2016 Accepted: June24, 2016 